Tracking sharks without teeth: a non-invasive rigid tag attachment for large predatory sharks

Chapple et al. 


\title{
Tracking sharks without teeth: a non-invasive rigid tag attachment for large predatory sharks
}

\author{
Taylor K. Chapple ${ }^{1 *}$, Adrian C. Gleiss', Oliver J. D. Jewell ${ }^{2,3,4}$, Martin Wikelski, $k^{5,6}$ and Barbara A. Block
}

\begin{abstract}
Background: Many marine species are difficult to study because components of their lifecycles occur solely or partially outside of the observable realm of researchers. Advances in biologging tags have begun to give us glimpses into these unobservable states. However, many of these tags require rigid attachment to animals, which normally requires catching and restraining the animals. These methods become prohibitive with large, dangerous, or rare species, such as large predatory sharks, and can have significant consequences for individual survival and behavior. Therefore, there is a need for methods and hardware to non-invasively and rigidly attach biologging tags to large predatory sharks that presents limited effects on the animals and researchers. Here we test a clamp tag and methods to non-invasively and rigidly attach biologging tags to white sharks (Carcharodon carcharias) in Gansbaai, South Africa.
\end{abstract}

Results: We developed stainless steel dorsal fin attachment clamps with abrasive pads for deployments of biologging devices on large marine organisms. We deployed 35 tags on 34 white sharks, which after modification, remained rigidly attached to the animals up to $93 \mathrm{~h}$, even through significant dynamic motions, and released from the animals with little or no effect on the animals.

Conclusion: These tags and attachments present a technique and hardware to equip large predatory sharks with biologging tags without the need to catch or restrain them, and with some additional modification, these tags may remain on the animals for long periods with potentially reduced risk for both researcher and animal.

Keywords: Shark, White shark, Biologging, Dorsal fin, Clamp, Accelerometer

\section{Background}

Initial studies of marine animals were dependent on direct observation of subject species, which required access to the animals in the wild or captive environments. However, the lifecycles of many marine species occur solely or partially outside of the observable realm of researchers, animals undertake movements or behaviors that cannot be studied in captive systems, or they cannot be appropriately maintained in captive facilities. The advent of animal-borne tags has provided an avenue to study some of these previously unobservable states. Initial acoustic and satellite tags provided information about the presence/absence, horizontal movements, vertical distribution, and temperature preferences of study animals $[1,2]$. Advances in miniaturization of biologging tags (e.g., with accelerometers, magnetometers, heart-

\footnotetext{
* Correspondence: tchapple@stanford.edu

${ }^{1}$ Hopkins Marine Station, Stanford University, 120 Oceanview Blvd, Pacific Grove, CA 93950, USA

Full list of author information is available at the end of the article
}

rate sensors, cameras, etc.) support increasingly complex studies of animals' movements, behaviors, physiology, and/or their environment (see [3, 4]).

A combination of recent advances in biologging technologies has the potential to record previously unobservable states in the most secretive and difficult to study species. Especially large sharks, where capture is either not feasible or dangerous to animal or researcher, require methodological solutions since successful use of many biologging tags requires a rigid or predictable attachment on the animal. Traditional external shark tags (acoustic and pop-off satellite) are typically attached to animals via a flexible tether and a subcutaneous dart, which allows the tags to "wobble" as the animal swims. This action of the tags masks the changes in animal movement making them indistinguishable from tag movement. This wobble also presents significant challenges for frame stability and consistent focus on the area of interest when cameras are included. As a result, rigid mounts have typically required capture (i.e., with 
hook and line) and restraint of the animal either in the water or onboard a vessel [5], which can have significant physiological consequences for the animals [6, 7]. Additionally, though the tags often aim to continuously record the natural behaviors of the animal, the animals' behaviors can be significantly influenced by the stress of capture/restraint $[8,9]$.

Gleiss et al. [10] introduced a clamp-tagging method on whale sharks (Rhincodon typus) that rigidly applied biologging tags via a specially designed tagging pole. Though this method works well for some large animals, characteristics of their methods preclude the use of these techniques with large predatory sharks. First, Gleiss et al. [10] swam with the whale sharks and applied the biologging tags underwater directly to the shark's fin. As white sharks (Carcharodon carcharias) are the largest predatory fish in the oceans, free-swimming with them to deploy tags presents a significant risk to researchers. Secondly, Gleiss et al. [10] used clamps with $1.5-\mathrm{cm}$ barbs to provide the anchoring of the units to the second dorsal fins. Though Gleiss et al. [10] found little effect from the tagging on the second dorsal fin of whale sharks, for white sharks, these biologging tags, which generally range in size from 100 to $500 \mathrm{~g}$, must be placed on the first dorsal fin. These fins are biologically critical for stability while fast swimming [11] and are used scientifically as means to uniquely identify individuals across decades [12] and estimate abundance [13, 14]. Additionally, some communities are dependent on white sharks for ecotourism, so there are sensitivities to the risk (or perceived risk) of damage to dorsal fins from attaching data loggers [15]. Therefore, attaching tags to the dorsal fin [16] could have significant biological and economic consequences that must be limited.

Therefore, it is advantageous to develop a method to attach biologging tags to large predatory sharks without catching or restraining the animals and with limited negative effects. To address this, we designed a modified rigid non-invasive fin clamp and attachment technique, based on Gleiss et al. [10], to deploy biologging tags on free-swimming white sharks. We attached these clamps, coupled with biologgers, at seasonal aggregation sites in Gansbaai, South Africa. This is the first time that this combination of sensors and attachment has been used on large white sharks. These methods do not require catching or restraining the animals, presenting an alternative method to rigidly attach biologging tags on large predatory marine animals while they free-swim with little risk to researchers, target species, and their recorded behaviors.

\section{Results}

We conducted baiting and tagging efforts on a total of 12 days (6 days in August 2013 and 6 days May 2014) with a total effort of $>88 \mathrm{~h}$ ( $45 \mathrm{~h}$ in August 2013 and 43 h in May 2014). During this ship time, we conducted 35 CATS tag deployment events (18 CATS Cams and 17 CATS Diaries) on 34 sharks (18 F:5 M). Following tagging, sharks typically continued to swim without an apparent change in behavior from the tagging. The estimated total length (TL) ranged from 2.1 to $4.3 \mathrm{~m}$ with an average size of $3.2 \mathrm{~m}$. Average deployment duration (except for those physically removed) was $22 \mathrm{~h}$ with the shortest deployment of $1 \mathrm{~h}$ (first deployment) and the longest deployment was $93 \mathrm{~h}$. All but two of the tags were retrieved as intended. The two tags not retrieved were observed on the animals but were not detected by radio signal during or after the expected deployment period. The failure of these two tags may have been a result of very high-frequency (VHF) pinger failure, tags releasing outside of the reception range or the flotation and/or VHFs being compromised by being bitten once released.

Our first CATS Cam tag deployment on 2.3-m white shark using a 118-N clamp slipped off the shark's fin after $1 \mathrm{~h}$. Upon download of the tag information, logged data revealed that there had been a rapid acceleration at the moment of detachment. Following this event, we used only the 196-N clamps to ensure that the tags remained on the animals during their dynamic movements. All of the subsequent CATS tags stayed on the animals as intended (except for those physically removed), even during significant dynamic motion. Review of the acceleration data indicated episodes of rapid acceleration throughout the dataset (Fig. 1a). We reviewed the pitch angle of the tag and the estimated velocity to determine if the tags remained rigidly attached without slipping throughout these episodes and the entire datasets (Fig. 1b). Pitch angle was estimated from the arcsine of the surge acceleration and was expected to optimally vary similarly to speed. Therefore, in each of our deployments (while the tags were attached), the constant and non-shifting relationship between these parameters indicated the tag did not slip.

To the best of our knowledge, all tags were released from the clamps at the predicted times for the galvanic time releases (GTRs) (normally 12-72 h) leaving only the clamps on the fins. We were able to corroborate the duration of attachment with the data recorded on the tags by the loggers. The corrosion rates of the magnesium sleeves (and GTRs) are dependent on water temperature and animal speed; therefore, their release times varied depending upon the movements of the sharks through different water temperatures. In general, based on continued opportunistic observation of previously tagged animals by the authors and commercial cage-boat operators, we found that the clamps fell off between 7 and 10 days post-deployment.

A number of sharks were visually identified from our research vessel boat or cage-diving operations that provided 


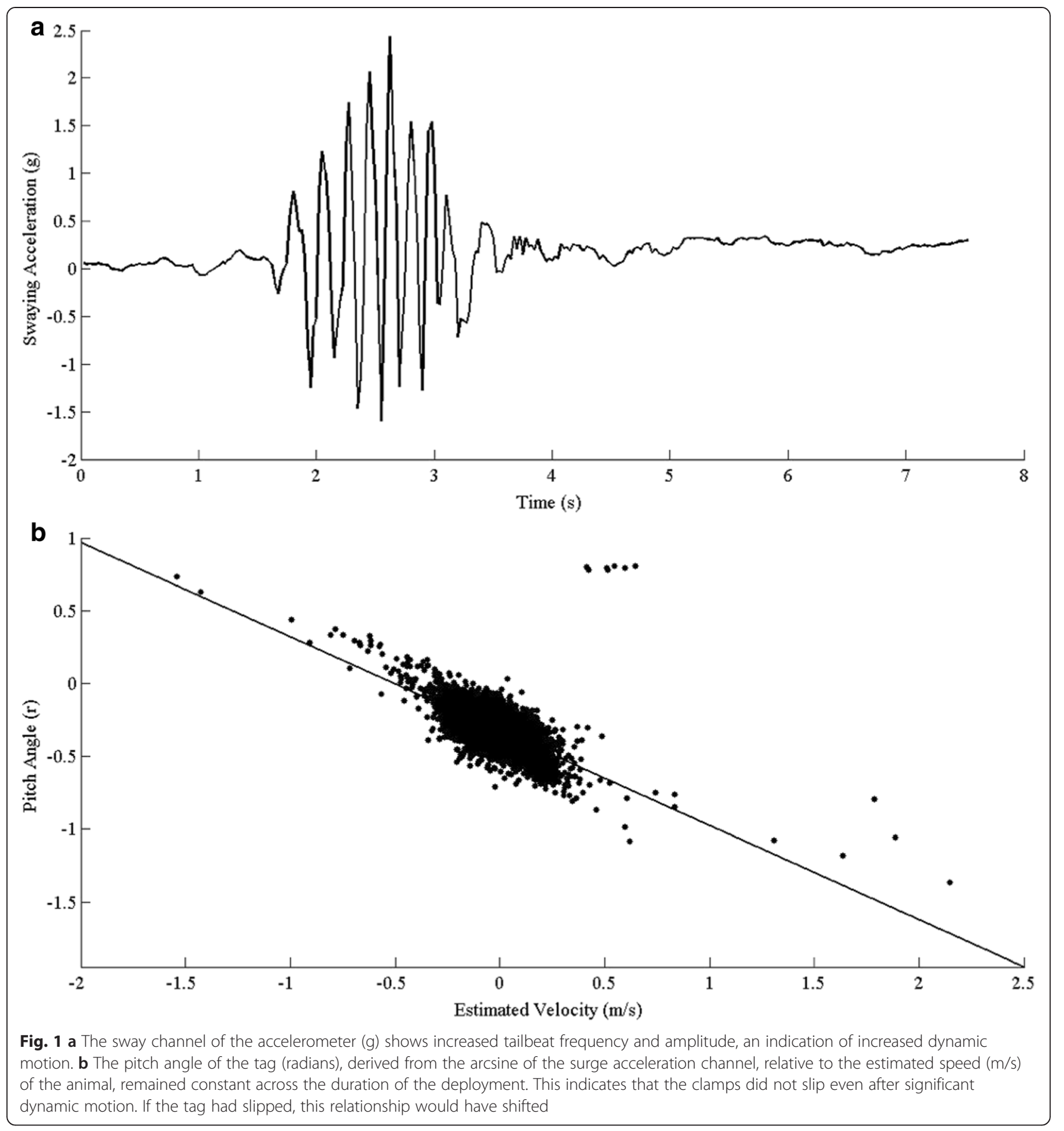

documentation on the corrosion process of the sleeves or with fin abrasion marks where clamps had recently fallen off. We directly observed a clamp falling from the fin on one occasion: a shark that had been tagged on May 6, 2014 and was resighted on May 11, 2014 with only the clamp remaining. While passively observing the shark for approximately $10 \mathrm{~min}$, we saw one clamp arm fall off, after which the clamp slipped up the fin and fell off the animal completely, leaving only slight abrasion marks (Fig. 2). This was the expected normal sequence of events. On a few occasions, the clamp arms (remaining after tag release but before the magnesium sleeve had completely corroded) were observed by cage-diving boat operators and were actively "knocked" free by allowing the floating baitline to rub up the fin as the shark swam by, releasing the clamp without apparent reaction by the animal. On two occasions, clamps stayed on unexpectedly after the magnesium sleeve corroded and were knocked off by boat operators or 


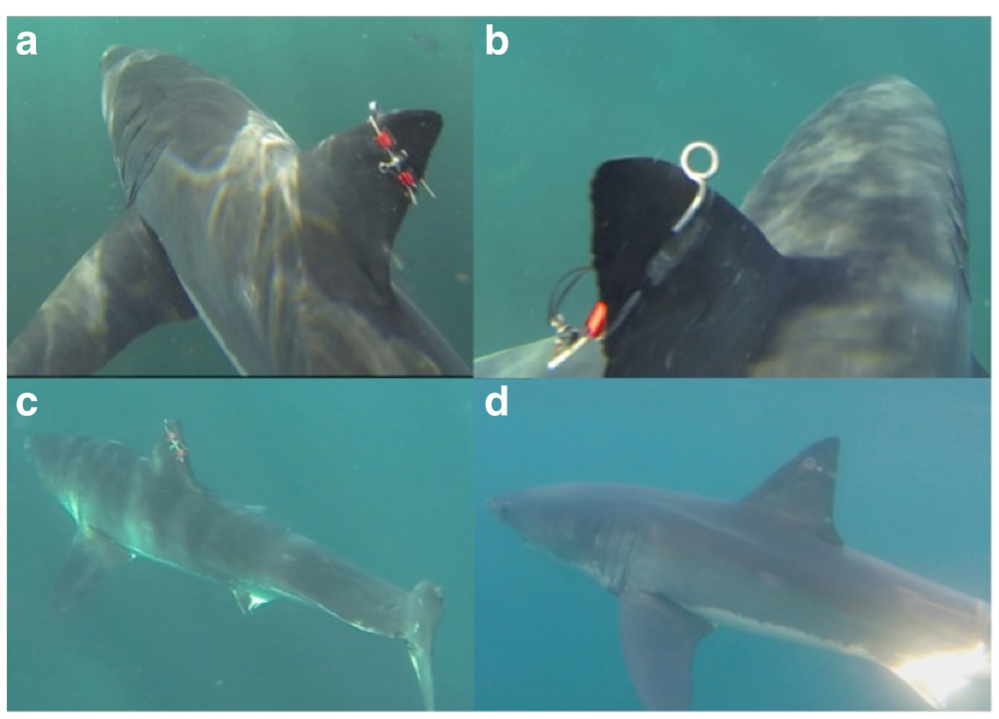

Fig. 2 a A 2.7-m TL male with the CATS Diary tag already released, but the clamp still attached - see the two ends of the clamp arms. b First, the magnesium sleeve corrodes and one clamp arm falls away. c Then the clamp slides up the fin and $\mathbf{d}$ falls off completely leaving only slight abrasions on the fin

researchers (E. Gennari and H. Otto pers. comm). In these instances, the clamps were contacted with a pole (Additional file 1: Figure S1) revealing superficial abrasion wounds. One of these sharks, tagged in May 2014 was resighted in March 2015 with the fin fully healed (Additional file 1: Figure S1). However, we made modifications to the clamps that will prevent similar injury from occurring in future deployments (see "Discussion" for description of modification).

\section{Discussion}

Our results present a new attachment method for placing biologging tags that require rigidity for data collection on large predatory sharks. This method does not require animals to be caught or restrained, and researchers can remain in a boat (though free-swimming attachment could also be possible with less dangerous animals). After adjustment of the clamp strength, we successfully demonstrate that noninvasive clamps can remain rigidly fixed on the animals, even during significant dynamic motion (Fig. 1). The majority of tags and clamps remained on the sharks for the desired period and released from the animals with only discoloration markings or, in the rare case of the two units that remained on for 5 weeks, superficial wounds on the first dorsal fin. Observations of sharks and data indicate that the animals display typical swimming behavior posttagging.

Clamp tags remained attached up to $93 \mathrm{~h}$ allowing highquality recordings and data collection from tags that required stability (Fig. 1). Two clamps stayed on longer than anticipated ( $\sim 5$ weeks); however, the units were easily knocked off the animals revealing superficial abrasion wounds. White sharks have been observed to heal from wounds quickly [17], and in March 2015, one of these sharks was resighted with the fin fully healed and only dark spots indicating evidence of the injury (Additional file 1: Figure S1). However, the fact that the clamps did not fall off as expected was initially troubling. After reviewing the footage of the clamps on the animals, it became apparent that the remaining nub from where the clamp arm was cut during production provided enough friction on large animals (i.e., thicker fins) to hold the clamp on. We later remedied this by cutting the clamps closer to the spring and on both sides. Though unreleased clamps were a rare event, these modifications will ensure that the clamps come fully off the animals in the future.

The clamp system performed favorably in comparison to the early versions containing short spikes trialed on whale sharks by Gleiss et al. [10]. Despite the lack of any piercing of tissue, clamps remained attached for desired durations and were easily deployed from a boat and in principal would perform equally well in species that can be attracted and tagged underwater. In comparison to the fin-clamping system developed by the National Geographic Imaging Unit (CritterCam), which relies on a large gas-pressure powered system capable of attaching tags to sharks from hours to days, our clamping system is small and lightweight (Chapple, Gleiss \& Liebsch, pers. obs.), requires little equipment for deployment, and is easily constructed in most basic metal workshops. However, direct performance comparisons of the attachments have not been performed. The obvious drawback of these types of system is the need to study species bold enough to approach boats or researchers. Additionally, longer deployments are necessary 


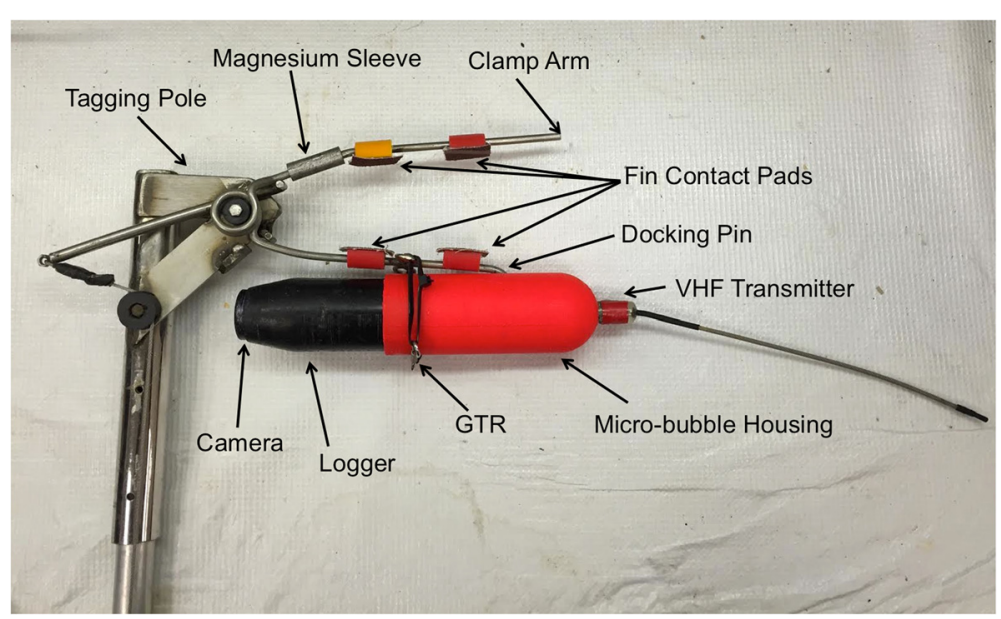

Fig. 3 Tag and attachment of device. A CATS Camera tag attached to the specially designed attachment clamp via a GTR and docking pin. The abrasive pads secure the clamp onto the fin until the magnesium sleeve corrodes and releases the clamp

to assess the use of these clamp systems with long-term tags.

\section{Conclusion}

We have further refined a new tool to equip sharks with the latest sensors available to animal biologists and as a result have opened the doors to studies on the ecology and physiology of some of the most difficult to study species. Our system is easy to implement in the field, for sharks that come within $1 \mathrm{~m}$ of the researcher and can be constructed without the need of a high-tech workshop. Importantly, this system does not require catching the animal on hook and line, effectively reducing the ill effects on the individual and any post-tagging trauma.

\section{Methods}

Fieldwork was conducted in the waters around Dyer Island, near Gansbaai, South Africa. Initial work, focused mainly at inshore aggregations sites, was conducted in August 2013. We conducted a second research expedition in May 2014 focused mainly in waters near Dyer Island and Geyser Rock.

We used a combination of CATS Diary tags (Customized Animal Tracking Solutions, Australia), which coupled a suite of biologging sensors (12 channels of data: tri-axial accelerometers, magnetometers and gyroscopes, depth, temperature, light and speed sensors) and CATS Cam tags, which housed a similar sensory arrays with an additional $1280 \times 720 \mathrm{HD}$ video camera at $30 \mathrm{fps}$. The Diary and Cam tags were encased in custom built micro-bubble and epoxy resin housing (see [18]) with a VHF pinger for retrieval (Fig. 3).

The CATS tags were attached to a specially constructed stainless steel spring clamp via a docking pin and a corrodible GTR (Neptune Marine Products, USA; Fig. 3).
Whereas Gleiss et al. [10] used 1.5-cm barbs to lock the clamp onto the fin, we used abrasive friction pads $(\sim 4 \times 4 \mathrm{~cm})$, which conformed to the dorsal fin and allowed the mount to stay on the fin at increased speeds without puncturing the skin. Because we only used friction pads and not barbs to attach to the fin, we increased the

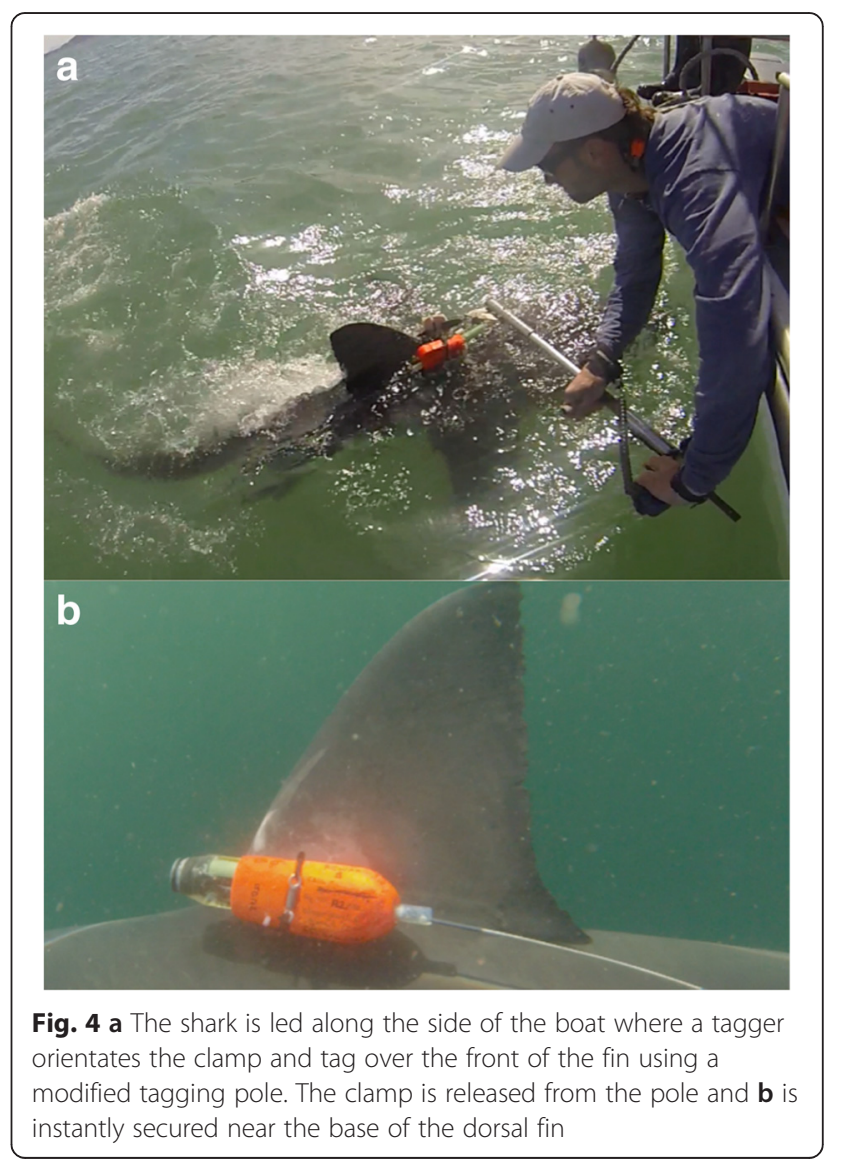


compression strength of the clamps. We increased the clamping strength to $118 \mathrm{~N}\left(\sim 18 \mathrm{kPa}\right.$ or $\left.1.8 \mathrm{~N} / \mathrm{cm}^{2}\right)$ and $196 \mathrm{~N}\left(\sim 30 \mathrm{kPa}\right.$ or $\left.3.1 \mathrm{~N} / \mathrm{cm}^{2}\right)$ to determine the appropriate amount of pressure.

A key component to non-invasive nature of the tag is the ability to passively release the unit from the animal after a given amount of time. To facilitate the predictable shedding of the clamp, one clamp arm was cut near the spring coil and was reconnected using a magnesium sleeve. Once in saltwater, after a relatively predictable period of time, the magnesium sleeve dissolved separating clamp from the arm, acting as a passive mechanism by which the complete spring system would release from the fin.

Sharks were attracted to the research vessel using a combination of macerated fish, fish heads, and a seal decoys. Instead of a tagger swimming parallel to the shark, as in Gleiss et al. [10], animals were led, so they swam parallel along the side of the boat by trailing a decoy or buoy with fish heads. The sharks normally were focused on the bait/ decoy and did not react to the tagger leaning over the side of the boat. As the animals swam along the side of the boat, the tagger used a $\sim 1.2-\mathrm{m}$ tagging pole to slide the units over the dorsal fin and released the clamp (see Additional file 2: Video S1) near the base of the dorsal fin (Fig. 4; Additional file 2: Video S1).

After a pre-set time, determined to increase probability of retrieving the tags, the GTR link corroded, and the tag unit floated free of the clamp and was found with a VHF receiver. This left only the clamp remaining on the animal until the magnesium sleeve corroded and released the entire clamp, leaving no hardware on the animal. This method aimed to ensure predictable passive release from the animal of the tag via the GTR and the clamp via the magnesium sleeve.

\section{Additional files}

Additional file 1: Longer duration attachment. Figure S1. (a) A rare case where a clamp remained for $\sim 5$ weeks on an animal, despite one clamp arm falling off. (b) In May, 2014 a boat operator contacts the tag with a pole to remove the clamp, leaving (c) superficial abrasions where the clamps were. (d) In March, 2015 the same animal was resighted with a fully healed dorsal fin exhibiting only dark spots where the abrasion occurred. These photos were used to modify the clamps so that similar injuries will not occur in the future. Photo credit: Hennie Otto and Kelly Baker, Marine Dynamics (www.sharkwatchsa.com).

Additional file 2: CATS tag attachment. As the white shark follows the bait to the boat, the CATS tag is clamped to the dorsal fin. The animal continues to free-swim, without being caught or restrained, throughout the tagging process.

\section{Competing interests}

The authors declare that they have no competing interests.

\section{Authors' contributions}

TKC conceived and coordinated the study, tagged the animals, analyzed the data, and drafted the manuscript. ACG conceived and coordinated the study, tagged the animals, and analyzed the data. OJDJ conceived and coordinated the study and tagged the animals. MW conceived the study, provided funding, and advised the project. BAB conceived the study, provided funding, and advised the project. All authors read and approved the final manuscript.

\section{Acknowledgements}

The authors would first like to thank N Liebsch and P Kraft at Customized Animal Tracking Solutions (CATS). We also thank W Chivell and D Chivell with Marine Dynamics and the Dyer Island Conservation Trust for logistical and vessel support for this project. We would also like to thank $\mathrm{H}$ Otto and K Baker for the use of their photos, A Boyd, J Cornelius, S Jorgensen, M Wcisel, A Towner, AB Casagrande IV, N Gormley, S Visagie, A Lynch, J Golbol, the Saxon Lodge, P du Toit, N Stelutto, E Gennari, and all the volunteers and staff at Marine Dynamics.

Funding was provided by Stanford University TAG A Giant fund and the National Geographic Society Expedition Councils Grant.

This research was conducted under DEA permit RES 2013/81 and RES2014/34.

\section{Author details}

${ }^{1}$ Hopkins Marine Station, Stanford University, 120 Oceanview Blvd, Pacific Grove, CA 93950, USA. ²Dyer Island Conservation Trust, Great White House, Geelbek St, Kleinbaai 7220, South Africa. ${ }^{3}$ Mammal Research Institute, University of Pretoria, Hatfield, Pretoria 001, South Africa. ${ }^{4}$ Netherlands Institute of Sea Research (NIOZ) Yerseke, Korringaweg 7, Yerseke, Zeeland 4401, Netherlands. ${ }^{5}$ Max Planck Institute for Ornithology, Radolfzell, Germany. ${ }^{6}$ Biology Department, University of Konstanz, Constance, Germany.

Received: 1 January 2015 Accepted: 9 May 2015

Published online: 01 June 2015

\section{References}

1. Grothues TM. A review of acoustic telemetry technology and a perspective on its diversification relative to coastal tracking arrays. In: Tagging and Tracking of Marine Animals with Electronic Devices. New York, NY: Springer; 2009. p. 77-90.

2. Hammerschlag N, Gallagher AJ, Lazarre DM. A review of shark satellite tagging studies. J Exp Mar Biol Ecol. 2011;398:1-8.

3. Boyd IL, Kato A, Ropert-Coudert Y. Bio-logging science: sensing beyond the boundaries. Mem Natl Inst Polar Res. 2004;58:1-14.

4. Rutz C, Hays GC. New frontiers in biologging science. Biol Lett. 2009;5:289-92.

5. Heithaus MR, Marshall GJ, Buhleier BM, Dill LM. Employing Crittercam to study habitat use and behavior of large sharks. Mar Ecol Prog Ser. 2001;209:307-10.

6. Danylchuk AJ, Suski CD, Mandelman JW, Murchie K, Haak CR, Brooks AML, et al. Hooking injury, physiological status and short-term mortality of juvenile lemon sharks (Negaprion bevirostris) following catch-and-release recreational angling. Conserv Physiol. 2014;2:cot036.

7. Gallagher AJ, Serafy JE, Cooke SJ, Hammerschlag N. Physiological stress response, reflex impairment, and survival of five sympatric shark species following experimental capture and release. Mar Ecol Prog Ser. 2014;496:207-18.

8. Thomson JA, Heithaus MR. Animal-borne video reveals seasonal activity patterns of green sea turtles and the importance of accounting for capture stress in short-term biologging. J Exp Mar Biol Ecol. 2014;450:15-20.

9. Sundström LF, Gruber SH. Effects of capture and transmitter attachments on the swimming speed of large juvenile lemon sharks in the wild. J Fish Biol. 2002;61:834-8.

10. Gleiss A, Norman B, Liebsch N, Francis C, Wilson R. A new prospect for tagging large free-swimming sharks with motion-sensitive data-loggers. Fish Res. 2009;97:11-6.

11. Lingham-Soliar T. Dorsal fin in the white shark, Carcharodon carcharias: a dynamic stabilizer for fast swimming. J Morphol. 2005;263:1-11.

12. Anderson SD, Chapple TK, Jorgensen SJ, Klimley AP, Block BA. Long-term individual identification and site fidelity of white sharks, Carcharodon carcharias, off California using dorsal fins. Mar Biol. 2011;158:1233-7.

13. Chapple TK, Jorgensen SJ, Anderson SD, Kanive PE, Klimley AP, Botsford LW, et al. A first estimate of white shark, Carcharodon carcharias, abundance off Central California. Biol Lett. 2011;7:581-3.

14. Towner AV, Wcisel MA, Reisinger RR, Edwards D, Jewell OJ. Gauging the threat: the first population estimate for white sharks in South Africa using photo identification and automated software. PLoS One. 2013;8:e66035. 
15. Hammerschlag N, Cooke SJ, Gallagher AJ, Godley BJ. Considering the fate of electronic tags: interactions with stakeholders and user responsibility when encountering tagged aquatic animals. Methods Ecol Evol. 2014;5:1147-53.

16. Jewell OJ, Wcisel MA, Gennari E, Towner AV, Bester MN, Johnson RL, et al. Effects of smart position only (SPOT) tag deployment on white sharks Carcharodon carcharias in South Africa. PLoS One. 2011;6, e27242.

17. Towner A, Smale MJ, Jewell O. Boat-strike wound healing in Carcharodon carcharias. In: Global Perspectives on the Biology and Life History of the White Shark. Boca Raton, FL: CRC Press; 2012. p. 77-84.

18. Liebsch NS. Hankering back to ancestral pasts: constraints on two pinnipeds, Phoca vitulina \& Leptonychotes weddellii foraging from a central place. Kiel: Univ., Diss; 2006. p. 2006

\section{Submit your next manuscript to BioMed Central and take full advantage of:}

- Convenient online submission

- Thorough peer review

- No space constraints or color figure charges

- Immediate publication on acceptance

- Inclusion in PubMed, CAS, Scopus and Google Scholar

- Research which is freely available for redistribution 